\title{
Energia Metabolizável de Ingredientes Determinada com Codornas Japonesas (Coturnix coturnix japonica $)^{1}$
}

\section{José Humberto Vilar da Silva ${ }^{2}$, Marinalva Barbosa da Silva ${ }^{3}$, Edson Lindolfo da Silva ${ }^{3}$, José Jordão Filho ${ }^{3}$, Marcelo Luís Gomes Ribeiro ${ }^{2}, 4$, Fernando Guilherme Perazzo Costa ${ }^{5}$, Wilson Moreira Dutra Júnior ${ }^{6}$}

RESUMO - O experimento um foi realizado para determinar a energia metabolizável aparente (EMA) e corrigida pelo balanço de nitrogênio (EMAn) de nove alimentos utilizando codornas japonesas em crescimento. No experimento dois, objetivou-se comparar formulações de rações utilizando EMAn do milho e do farelo de soja determinada para frangos de corte e poedeiras, com aquelas determinadas com codornas com 22 a 27 dias de idade e 65 dias de idade. No experimento um, foram utilizadas 400 codornas em crescimento recebendo uma dieta basal (DB) e nove misturas compostas por $70 \%$ da DB $+30 \%$ dos alimentos testes, totalizando dez tratamentos, cada um com quatro repetições de dez aves. No experimento dois, 160 codornas européias em postura receberam três tratamentos durante três períodos de 15 dias de duração, com doze repetições de cinco aves. Os valores de EMA e EMAn ( $\mathrm{kcal} / \mathrm{kg}$ ) determinados para os alimentos de origem vegetal foram, respectivamente, 3.340 e 3.354 para o milho moído, 2.718 e 2.456 para o farelo de soja, 3.453 e 3.084 para a soja integral extrusada, 1.624 e 1.593 para o farelo de trigo, 4.558 e 3.992 para o farelo de glúten de milho, 3.329 e 3.378 para a farinha de mandioca e 1.238 e 1.223 para a farinha integral da vagem de algaroba e para os alimentos de origem animal, respectivamente, de 2874 e 2453 para a farinha de peixe e 3090 e 2791 para a farinha de vísceras. A EMAn do milho e do farelo de soja estimada com codornas não melhorou o consumo, produção, peso e conversão por massa de ovos, validando o uso da energia desses ingredientes determinada com frangos de corte e poedeiras para compor rações para codornas.

Palavras-chave: alimentos alternativos, codornas, determinação da energia metabolizável

\section{Metabolizable Energy of Feedstuffs Determined in Japanese Quails (Coturnix coturnix japonica)}

ABSTRACT - The experiment one was carried out to determine apparent metabolizable energy (AME) and nitrogen-corrected ME (AMEn) of nine feedstuffs in Japanese quails. The objective of the experiment two was to compare diets formulated with AMEn of corn and soybean meal, usually fed to broilers and laying hens, with diets formulated with AMEn determined in growing (22 days of age) and adult quails ( 65 days of age). In the experiment one, 400 growing quails were fed a basal diet (BD) and nine test diets (70\% BD $+30 \%$ feedstuffs test), with a total of ten diets with four replicates of ten birds each. In the experiment two, 160 European quails were randomized allotted to three treatments, with twelve replicates of five birds, and fed during three periods of fifteen days. The AME and AMEn values (kcal/kg) for vegetal feedstuffs were: 3,340 and 3,354 for corn, 2,718 and 2,456 for soybean meal, 3,453 and 3,084 for integral soybean extruded, 1,624 and 1,593 for wheat bran, 4,558 and 3,992 for corn gluten meal, 3,329 and 3,378 for cassava flour and 1,238 and 1,223 to integral mesquite pods meal. The animal feedstuffs had 2,874 and 2,453 for fish meal and 3,090 and 2,791 for poultry meal. The AMEn of corn and soybean meal estimated for quail did not improve feed intake, egg production, egg weight and feed egg mass ratio, supporting the validity of use of energy those ingredients obtained with broiler and laying hens for formulated quail diets.

Key Words: alternative feedstuffs, metabolizable energy determination, quail

\section{Introdução}

A energia é o principal componente nutricional da ração, determinando o desempenho das aves. A energia não é um nutriente, mas resulta da oxidação dos nutrientes durante o metabolismo, sendo liberada na forma de calor ou sendo armazenada para uso posterior nos processos metabólicos do organismo animal (NRC, 1994).

Em sistema de criação onde se utiliza alimentação à vontade, o consumo alimentar é regulado pela densidade energética da ração e pela exigência das

\footnotetext{
${ }^{1}$ Parte da dissertação do segundo autor.

2 Professor do Departamento de Agropecuária-CFT-UFPB-Campus IV.Bananeiras, PB.CEP:58225-000.E.mail: jvilar@infowebpb.com.br

${ }^{3}$ Aluna do Mestrado em Produção Animal - Departamento de Zootecnia - CCA-UFPB-Campus III. Areia, PB. CEP: 58397-000.

E.mail: cca@ufpb.br

${ }^{4}$ Aluno do Doutorado Integrado - DZ-CCA-UFRPE-UFC. Areia, PB. CEP: 58397-000.

5 Professor do DZ-CCA-UFPB, Areia, PB. CEP: 58397-000 E.mail: fperazzo@cca.ufpb.br

6 Professor do DZ-UFRPE, Recife, PE. CEP: 50060-130. E.mail: dutrawm@bol.com.br
} 
aves, tornando-se imprescindível o conhecimento acurado da energia dos alimentos para proporcionar $o$ adequado balanceamento das dietas. No entanto, a efetividade do método de formulação de rações é dependente da precisão com que a energia dos alimentos é determinada. Matterson et al. (1965) citam que o conhecimento prévio dos valores energéticos dos alimentos é necessário para formulação precisa e econômica das rações para aves.

Muitos fatores podem interferir nos resultados das avaliações de energia dos alimentos, entre os mais importantes podem-se citar: idade, procedimento experimental, granulometria e processamento (Penz Jr. et al., 1999), espécie animal envolvida.

No balanceamento de rações para codornas, empregam-se valores de energia para o milho e farelo de soja usados para frangos de corte e poedeiras. Entretanto, em virtude de as codornas apresentarem maior velocidade de passagem dos alimentos pelo trato gastrintestinal, podem ocorrer diferenças marcantes entre essas espécies na digestibilidade e aproveitamento dos alimentos.

Murakami \& Furlan (2002) mencionaram que esta extrapolação parece incorreta, uma vez que o aproveitamento de determinado alimento e seu valor energético são influenciados pela taxa de passagem no trato digestório, que também está relacionado com uma série de variáveis, como a quantidade de alimento ingerido, composição do alimento, aspecto físico do alimento, conteúdo de umidade, freqüência e tempo de fornecimento do alimento, além das variações individuais.

Este trabalho foi conduzido com os objetivos de estimar o valor energético de ingredientes alimentares de origem vegetal e animal de rações e avaliar o desempenho de codornas japonesas em postura alimentadas com rações formuladas com base na energia do milho e do farelo de soja estimada para frangos e poedeiras em relação às rações formuladas com níveis energéticos estimados com codornas japonesas com 22 a 27 dias e com 65 dias de idade.

\section{Material e Métodos}

O experimento foi conduzido numa sala do Laboratório Avícola do Campus de Bananeiras da Universidade Federal da Paraíba.

Experimento 1. Determinação dos valores energéticos dos alimentos

O delineamento experimental utilizado foi o inteiramente ao acaso, com dez tratamentos (nove alimentos testes e uma dieta basal), constituídos por quatro repetições de dez aves, num total de 400 codornas mistas (machos e fêmeas), pesando $52 \mathrm{~g}$ aos 17 dias de idade, alojadas em gaiolas de arame galvanizado com dimensões de $33 \times 38 \times 16 \mathrm{~cm}$, tendo abaixo uma bandeja de isopor plastificada para as coletas de excretas individualizadas, por parcela experimental. As codornas receberam rações e água à vontade e foram submetidas a um programa de luz de 24 horas de duração (luz natural + luz artificial).

O período de coleta teve início quando as aves completaram 22 dias e se estendeu até os 27 dias de idade. Foi utilizado o método tradicional de coleta total de excretas, usando o óxido férrico (2\%) como marcador fecal para sinalizar o início e final das coletas. Foram anotados também os tempos de aparecimento das excretas marcadas, com o auxílio de um observador para cada tratamento, para identificar o tempo de passagem do alimento pelo trato gastrintestinal, este procedimento foi realizado duas vezes. As coletas foram realizadas duas vezes ao dia em intervalos de 12 horas ( 5 e $17 \mathrm{~h}$ ).

Os alimentos vegetais testados foram o milho moído, farelo de soja, soja integral extrusada, farelo de glúten de milho, farelo de trigo, farinha de mandioca e farinha integral de algaroba, e os de origem animal foram farinha de peixe e farinha de vísceras de aves (Tabela 1) que substituíram a dieta basal (DB) em 30\%, na base da matéria natural. A composição da DB é apresentada na Tabela 2.

Os valores de temperatura e umidade foram registrados diariamente em dois horários $(8$ e 17 h), e as médias máximas e mínimas de temperatura foram, respectivamente, de 22,5 e $30,3^{\circ} \mathrm{C}$, e de umidade foram de 60,7 e $91,8 \%$.

As excretas foram colocadas em sacos plásticos, pesadas e armazenadas em freezer a $-12{ }^{\circ} \mathrm{C}$ até o final do período de coleta. Posteriormente, foram descongeladas, reunidas por repetição, homogeneizadas, pesadas e colocadas em estufa de ventilação forçada durante 72 horas, para pré-secagem a $55^{\circ} \mathrm{C}$. Em seguida, as amostras foram pesadas, moídas e acondicionadas em recipiente apropriado e usada nas determinações de matéria seca, proteína bruta (nitrogênio) e energia bruta, de acordo com Silva (1990). A energia bruta foi determinada em bomba calorimétrica adiabática Parr e o nitrogênio em aparelho semi-micro Kjeldahl.

A ração referência (Tabela 2) foi formulada de acordo com Silva \& Ribeiro (2001), sendo substituída em $30 \%$ pelos alimentos testes (Hill \& Anderson, 
1958). A quantidade de ração ingerida em cada parcela experimental foi anotada e amostras das rações referência e testes foram obtidas para as análises químicas posteriores.

Os valores de energia metabolizável aparente (EMA) e corrigida pelo balanço de nitrogênio (EMAn) foram determinados pela equação de Matterson et al. (1965), enquanto o coeficiente de metabolização da EB foi obtido pela porcentagem de EB convertida em EMAn (ARC, 1980).

Os valores percentuais do coeficiente de metabolização da energia bruta (CMEB) foram sub-

Tabela 1 - Umidade, matéria seca (MS), proteína bruta (PB) e energia bruta (EB) dos alimentos estudados na matéria natural $^{1}$

Table 1 - Humidity, dry matter (DM), crude protein (CP) and gross energy of feedstuffs as fed

\begin{tabular}{|c|c|c|c|c|}
\hline $\begin{array}{l}\text { Alimento } \\
\text { Feedstuffs } \\
\end{array}$ & $\begin{array}{l}\text { Umidade } \\
\text { Humidity }\end{array}$ & $\begin{array}{l}\text { MS } \\
D M\end{array}$ & $\begin{array}{l}\mathrm{PB} \\
C P \\
\end{array}$ & $\begin{array}{c}\mathrm{EB}(\mathrm{kcal} / \mathrm{kg}) \\
G E\end{array}$ \\
\hline \multicolumn{5}{|l|}{ Origem vegetal(Vegetal origin) } \\
\hline Milho moído (Corn ground) & 11,6 & 88,4 & 6,8 & 4.497 \\
\hline Farelo de soja (Soybean meal) & 12,2 & 87,8 & 41,4 & 4.899 \\
\hline Soja extrusada (Extruded soybean) & 7,2 & 92,8 & 34,9 & 5.687 \\
\hline Farelo de glúten (Gluten bran) & 8,8 & 91,2 & 57,5 & 5.754 \\
\hline Farelo de trigo (Wheat bran) & 11,7 & 88,3 & 13,3 & 4.443 \\
\hline Farinha de mandioca (Cassava flour) & 7,0 & 93,0 & 1,4 & 4.034 \\
\hline F. integral da vagem de algaroba (Integral mesquite pods meal) & 12,8 & 87,2 & 11,8 & 4.442 \\
\hline \multicolumn{5}{|l|}{ Origem animal (Animal origin) } \\
\hline Farinha de peixe (Fish meal) & 6,7 & 93,3 & 48,3 & 4.261 \\
\hline Farinha de víscera (Poultry offal meal) & 6,3 & 93,7 & 48,3 & 4.294 \\
\hline
\end{tabular}

${ }^{1}$ Valores analisados no Laboratório de Nutrição Animal - CCA/UFPB.

Tabela 2 - Composição química e calculada da ração basal ${ }^{1}$

Table 2 - Chemical and calculate composition of basal diet ${ }^{1}$

\begin{tabular}{|c|c|}
\hline Alimento (Feedstuffs) & $\%$ \\
\hline Milho $(6,8 \% \mathrm{~PB})^{2}$ (Corn grain) & 50,150 \\
\hline Farelo de soja $(41,4 \% \text { PB })^{2}$ (Soybean meal) & 43,116 \\
\hline Calcário (Limestone) & 1,324 \\
\hline Fosfato bicálcico (Phosphate dicalcium) & 1,553 \\
\hline DL-metionina $(99 \%)$ (DL-methionine) & 0,272 \\
\hline L-lisina $\cdot \mathrm{HCl}(78,4 \%)($ L-lysine $? \mathrm{HCl})$ & 0,393 \\
\hline Cloreto de colina $(70 \%)$ (Choline chroline) & 0,101 \\
\hline Óleo de soja (Soybean oil) & 2,654 \\
\hline Sal comun (Comum salt) & 0,277 \\
\hline Premix vitamínico ${ }^{3}$ & 0,100 \\
\hline Premix mineral $^{4}$ & 0,050 \\
\hline $\mathrm{BHT}^{5}$ & 0,010 \\
\hline \multicolumn{2}{|l|}{ Composição química (Chemical composition) } \\
\hline Proteína bruta (Crude protein) & 24,10 \\
\hline EMn (calculada) MEn (Calculated) & 2960 \\
\hline EMn (analisada) ${ }^{2}$ MEn (Analyzed) & 2990 \\
\hline Cálcio (Calcium) & 1,30 \\
\hline Fósforo disponível (Available phosphorus) & 0,60 \\
\hline Metionina (Methionine) & 0,60 \\
\hline Metionina+cistina (Methionine + cystine $)$ & 0,88 \\
\hline Lisina (Lysine) & 1,30 \\
\hline Sódio (Sodium) & 0,16 \\
\hline
\end{tabular}

\footnotetext{
${ }_{1}^{1}$ Recomendações nutricionais segundo Silva \& Ribeiro (2001) (Nutritional recomendation by Silva \& Ribeiro, 2001).

2 Valores analisados no Laboratório de Nutrição Animal-CCA/UFPB (Values from Laboratory of Animal Nutrition-CCA/UFPB).

3 Premix vitamínico (Níveis/Kg do produto): Vitamina A 10.000.000 U.I, Vitamina $\mathrm{D}_{3} 2.500 .000$ U.I, Vitamina E 6.000 U.I, Vitamina K 1.600 $\mathrm{mg}$, Vitamina $\mathrm{B}_{12} 11.000$, Niacina (Niacin) $25.000 \mathrm{mg}$, Ácido Fólico (Folic acid) $400 \mathrm{mg}$, Ácido Pantotênico (Pantotenic acid) $10.000 \mathrm{mg}$, Selênio (Se) $300 \mathrm{mg}$, antioxidante (antioxidant) $20 \mathrm{~g}$, veículo (vehicle) Q.S.P.

${ }_{5}^{4}$ Premix mineral (Níveis/kg do produto): Mn 150.000mg, Zn 100,000mg, Fe 100.000 mg, Cu 16.000 mg, I 1.500 mg, veículo (vehicle) q.s.p. ${ }^{5} \mathrm{BHT}$ (antioxidante).
} 
metidos à correção pelo fator arco seno e analisados pelo teste $\mathrm{F}(\mathrm{P}<0,05)$. A significância das médias dos CMEB foi comparada pelo teste Student Newmann Keuls $(\mathrm{P}<0,05)$, por meio do Sistema para Análises Estatísticas e Genéticas - SAEG (Universidade Federal de Viçosa, 1983).

\section{Experimento 2. Desempenho}

Três rações foram elaboradas e fornecidas as codornas durante três períodos de quinze dias de duração para testar a validade do uso dos valores energéticos do milho e farelo de soja usados para frangos de corte e poedeiras, constantes em Rostagno et al. (2000), em comparação com os valores obtidos no ensaio anterior com codornas japonesas em crescimento (22 dias) e aqueles obtidos com codornas adultas (65 dias de idade) verificados por Furlan et al. (1998).
Foram utilizadas 180 codornas européias (Coturnix coturnix coturnix) com idade inicial de 100 dias, durante a fase de postura, em um delineamento experimental inteiramente ao acaso com três tratamentos e 12 repetições de cinco aves cada.

As aves foram alojadas em gaiolas de arame galvanizado com dimensões de 33 x 38 x $16 \mathrm{~cm}$ em galpão aberto, e foram submetidas a um programa de luz de 17 horas.

As aves foram alimentadas com três rações formuladas de acordo com Silva \& Ribeiro (2001) para conter $20 \%$ de proteína e $2800 \mathrm{kcal}$ de EMAn (Tabela 3). As rações à base de milho e farelo de soja foram elaboradas considerando os valores energéticos usados para formular rações de frangos de corte e poedeiras, constantes em Rostagno et al. (2000), a

Tabela 3 - Composição química e calculada das rações experimentais ${ }^{1}$

Table 3 - Chemical and calculated composition of the experimental diets

\begin{tabular}{|c|c|c|c|}
\hline Alimento(Feedstuffs) & $\operatorname{EMAn}^{2}(A M E n)$ & EMAn $^{3}(A M E n)$ & $\operatorname{EMAn}^{4}(A M E n)$ \\
\hline Milho $(6,8 \% \text { PB })^{5}$ (Corn grain) & 59,251 & 58,053 & 56,575 \\
\hline Farelo de soja $(41,4 \% \mathrm{~PB})^{5}$ (Soybean meal) & 32,682 & 32,905 & 33,181 \\
\hline Calcário (Limestone) & 5,613 & 5,610 & 5,606 \\
\hline Fosfato bicálcico (Dicalcium phosphate) & 1,300 & 1,303 & 1,306 \\
\hline DL-metionina $(99 \%)($ DL-methionine $)$ & 0,066 & 0,068 & 0,070 \\
\hline Cloreto de colina (70\%) (Choline chroline) & 0,100 & 0,100 & 0,100 \\
\hline Sal comun (Salt) & 0,277 & 0,277 & 0,278 \\
\hline Premix vitamínico ${ }^{6}$ (Vitamin premix) & 0,150 & 0,150 & 0,150 \\
\hline Premix mineral $^{7}$ & 0,100 & 0,100 & 0,100 \\
\hline $\mathrm{BHT}^{8}$ & 0,010 & 0,010 & 0,010 \\
\hline Areia lavada (Washed sand) & 0,451 & 1,424 & 2,624 \\
\hline Total & 100,000 & 100,000 & 100,000 \\
\hline \multicolumn{4}{|l|}{ Composição química (Chemical composition) } \\
\hline Proteína bruta (Crude protein) & 20,000 & 20,000 & 20,000 \\
\hline EMn (calculada) (MEn [calculated]) & 2800 & 2800 & 2800 \\
\hline Cálcio(Calcium) & 2,600 & 2,600 & 2,600 \\
\hline Fósforo disponível (Available phosphorus) & 0,350 & 0,350 & 0,350 \\
\hline Metionina (Methionine) & 0,379 & 0,380 & 0,381 \\
\hline Metionina+cistina (Methionine + cystine) & 0,700 & 0,700 & 0,700 \\
\hline Lisina (Lysine) & 1,057 & 1,060 & 1,064 \\
\hline Treonina (Threonine) & 0,777 & 0,777 & 0,777 \\
\hline Triptofano (Tryptophan) & 0,248 & 0,249 & 0,250 \\
\hline Sódio (Sodium) & 0,150 & 0,150 & 0,150 \\
\hline
\end{tabular}

${ }_{1}^{1}$ Recomendações nutricionais segundo Silva \& Ribeiro (2001) (Nutritional recomendation by Silva \& Ribeiro, 2001).

2 Ração formulada com valores energéticos normalmente usados para frangos e poedeiras (Rostagno et al., 2000) (Diet formulated with energy values usually used for poultry and laying hens, according to Rostagno et al., 2000).

${ }^{3}$ Ração formulada com valores energéticos determinados com codornas jovens (Diet formulated with energy values obtained with start growth quail).

4 Ração formulada com valores energéticos determinados com codornas adultas (Murakami \& Furlan, 2002) (Diet formulated with energy values obtained with finishing quails).

5 Valores analisados no Laboratório de Nutrição Animal-CCA/UFPB (Values from Laboratory of Animal Nutrition-CCA/UFPB).

${ }^{6}$ Premix Vitaminico. (Níveis/kg do produto): Vit. A 10.000 .000 U.I, Vit. $D_{3} 2.500 .000$ U.I, Vit. E 6.000 U.I, Vit. K 1.600 mg, Vit. $B_{12} 11.000$, Niacina (Niacin) $25.000 \mathrm{mg}$, Ácido fólico (Folic acid) $400 \mathrm{mg}$, Ácido pantotênico (Panthotenic acid) $10.000 \mathrm{mg}$, Se $300 \mathrm{mg}$, antioxidante (antioxidant) $20 \mathrm{~g}$, Veículo (Vehicle) Q.S.P.

7 Premix mineral (Níveis/kg do produto): Mn 150.000 mg, Zn 100,000 mg, Fe 100.000 mg, Cu 16.000 mg, I 1.500 mg, veículo q.s.p

${ }^{8}$ BHT (Antioxidante). 
energia determinada no ensaio anterior com codornas japonesas em crescimento ( 22 a 27 dias de idade) e aquela determinada com codornas adultas ( 65 dias de idade) constantes em Furlan et al. (1998).

As variáveis estudadas consumo de ração, variação de peso, produção de ovos, peso dos ovos, massa de ovos e conversão pela massa de ovos produzida foram medidas ao final dos três períodos de 15 dias.

As análises estatísticas foram realizadas utilizando o Sistema para Análises Estatística e Genéticas SAEG (UFV, 1983).

\section{Resultados e Discussão}

\section{Experimento 1. Determinações da energia metabolizável}

Os valores de energia metabolizável aparente (EMA), energia metabolizável aparente corrigida pelo balanço de nitrogênio (EMn) e dos coeficientes de metabolização da energia bruta (CMEB) estão apresentados na Tabela 4.

O farelo de glúten apresentou os maiores valores de EMA e EMAn, enquanto a farinha integral de vagem de algaroba (FVA), os menores.

$\mathrm{O}$ farelo de trigo e a farinha integral da vagem de algaroba, também apresentaram baixos valores energéticos. Os valores obtidos de EMA e EMn do farelo de trigo, respectivamente, de $1.624 \mathrm{e} 1.593 \mathrm{kcal}$ utilizando codornas japonesas de 22 a 27 dias de idade são inferiores aos apresentados por Murakami \& Furlan (2002), que foram de 2.400 e 2.400 obtidos com codornas aos 65 dias de idade, e o valor de EMAn constante em Rostagno et al. (2000) de $1.888 \mathrm{kcal}$.

Os valores de EMn obtidos com codornas de 22 a 27 dias de idade, foram inferiores àqueles verificados por Furlan et al. (1998), utilizando codornas com 65 dias de idade para o milho (3353 vs. $3.429 \mathrm{kcal})$, farelo de soja ( 2455 vs. $2592 \mathrm{kcal}$ ) e farelo de trigo (1593 vs. $2399 \mathrm{kcal}$ ) e menor que aquele apresentado por Murakami \& Furlan (2002), obtidos com codornas com 65 dias de idade e maior que aquele da farinha de peixe ( $2453 \mathrm{vs.} 2285 \mathrm{kcal}$ ).

Os fatores relacionados com a baixa capacidade das codornas jovens aproveitarem os alimentos em comparação com codornas mais velhas ainda não foram estudados, mas é possível inferir que o menor tempo de trânsito do alimento pelo trato gastrintestinal nas codornas jovens pode estar envolvido.

Murakami \& Furlan (2002) descreveram os tempos de passagem para o milho moído, farelos de soja e de trigo de, respectivamente, 97,3; 82,3 e 75,8 minutos para codornas aos 65 dias de idade, enquanto os resultados verificados utilizando codornas com 22 a 27 dias de idade mostraram que as misturas da $\mathrm{DB}+30 \%$ de milho ou farelo de soja ou farelo de trigo apresentaram velocidades de trânsito mais rápidas, respectivamente, de 63,0; 60,9 e 61,4 minutos.

Murakami \& Furlan (2002) verificaram que o uso dos valores de energia metabolizável dos alimentos

Tabela 4 - Valores energéticos (kcal), coeficiente de metabolização da energia bruta (CMEB) e erro-padrão de alguns alimentos para codornas (expressos na matéria natural) ${ }^{1}$

Table 4 - Energy values (kcal), coefficient of metabolization of gross energy (MGEC) and standard error of some feedstuffs fed to quails (as fed) ${ }^{1}$

\begin{tabular}{llll}
\hline Alimento (Feedstuffs) & EMA (AMEn) & EMAn $^{3}(A M E n)$ & CMEB $(\%)(M G E C)$ \\
\hline Origem vegetal(Vegetal origin) & & & \\
Milho (Corn ground) & $3340 \pm 63,35$ & $3354 \pm 63,99$ & $74,57 \pm 1,42^{\mathrm{b}}$ \\
Farelo de soja (Soybean meal) & $2718 \pm 132,54$ & $2456 \pm 123,16$ & $50,12 \pm 2,51^{\mathrm{f}}$ \\
Soja integral extrusada (Extruded integral soybean) & $3453 \pm 46,96$ & $3084 \pm 45,70$ & $54,22 \pm 0,80^{\mathrm{ef}}$ \\
Farelo de glúten (Corn gluten meal) & $4558 \pm 64,45$ & $3992 \pm 65,48$ & $69,37 \pm 1,14^{\mathrm{c}}$ \\
Farelo de trigo (Wheat bran) & $1624 \pm 74,06$ & $1593 \pm 67,53$ & $35,86 \pm 1,52^{\mathrm{g}}$ \\
Farinha de mandioca (Cassava flour) & $3329 \pm 27,40$ & $3378 \pm 26,51$ & $83,74 \pm 0,66^{\mathrm{a}}$ \\
FVA $^{2}$ & $1238 \pm 62,15$ & $1223 \pm 58,87$ & $27,54 \pm 1,35^{\mathrm{h}}$ \\
Origem animal (Animalorigin) & & & \\
Farinha de peixe (Fish meal) & $2874 \pm 68,92$ & $2453 \pm 65,32$ & $57,57 \pm 1,53^{\mathrm{e}}$ \\
Farinha de víscera (Viscera meal) & $3090 \pm 67,44$ & $2791 \pm 65,08$ & $65,00 \pm 1,52^{\mathrm{d}}$ \\
\hline
\end{tabular}

\footnotetext{
1 Obtidos com codornas de 22 a 29 dias de idade. EMA = energia metabolizável aparente; EMn = energia metabolizável aparente corrigida pelo balanço de nitrogênio (obtained with growth quail from 22 to 29 dys of age. AME = apparent metabolizable enegy; AMEn = apparent metabolizable energy nitrogen-corrected).

2 FVA = farinha integral de vagem de algaroba (integral mesquite pods meal).
} 
utilizados para poedeiras comerciais na formulação de rações para codornas parece indevido, pois um dos fatores que influencia o aproveitamento de determinado alimento e o seu valor energético é a taxa de passagem pelo trato digestório, e este se relaciona com uma série de variáveis, como a quantidade do alimento ingerido, composição do alimento, aspecto físico, conteúdo de água, frequiência e tempo de oferecimento do alimento, além das variações individuais.

Por ordem, a taxa de passagem da farinha de vísceras $(76,5 \mathrm{~min})$ foi maior que a do farelo de glúten (71,2 min), farinha de mandioca (66,9 min), farinha de peixe $(65,6 \mathrm{~min})$, farinha integral de vagem de algaroba (63,0 min), farelo de trigo $(61,4$ $\mathrm{min})$, milho (61,2 $\mathrm{min})$, farelo de soja (60,9 $\mathrm{min}) \mathrm{e}$ soja integral extrusada (60,9 min). A DB apresentou tempo médio de retenção de 60,3 min.

O coeficiente de metabolização da energia bruta foi maior na farinha de mandioca que no milho moído, farelo de glúten, farinha de vísceras, farinha de peixe, soja integral extrusada, farelo de soja, farelo de trigo, farinha integral de algaroba e farinha de carne e ossos (Tabela 4). O coeficiente de metabolização da energia bruta do farelo de soja não diferiu daquele da soja extrusada, mas foi inferior ao apresentado pelo farelo de glúten e farinha de peixe $(\mathrm{P}<0,05)$.

Os coeficientes de metabolização da energia bruta obtidos neste experimento com codornas de 22 a 27 dias de idade de $74,57 \%$ para o milho, $50,12 \%$ para o farelo de soja e de $35,86 \%$ para o farelo de trigo foram menores que os obtidos por Furlan et al. (1998), os quais obtiveram, com codornas com 65 dias de idade, valores de $88,99 \%$ para o milho, $63,29 \%$ para o farelo de soja e $60,88 \%$ para o farelo de trigo.

Comparando os valores observados para energia obtidos através das codornas de 22 a 27 dias de idade com os valores energéticos usados para frangos de corte e poedeiras, constantes em Rostagno et al. (2000), verificou-se maior semelhança entre os valores de energia do milho ( 3.353 vs. $3.371 \mathrm{kcal}$ ), farelo de soja ( 2.455 vs. $2.266 \mathrm{kcal})$, farinha de peixe $(2.453$ vs. $2.627 \mathrm{kcal})$ e farinha de vísceras $(2.791 \mathrm{vs}$. $2.934 \mathrm{kcal})$ e maiores diferenças para soja integral extrusada ( 3.083 vs. $3.460 \mathrm{kcal}$ ), farelo de trigo ( 1.593 vs. $1.888 \mathrm{kcal})$ e farinha integral de vagem de algaroba (1.223 vs. $1.520 \mathrm{kcal})$.

A farinha de mandioca, muito usada na alimentação humana na região Nordeste, mostrou-se uma excelente fonte energética para codornas, podendo ser testada em substituição ao milho tendo o cuidado de incluir um corante para pigmentar a gema dos ovos e uma fonte protéica de baixo custo, em virtude da farinha de mandioca ser pobre em pigmentantes e de baixo conteúdo protéico.

Os resultados deste experimento são similares aos verificados por Murakami \& Furlan (2002) e reforçam a necessidade de uso dos valores de energia obtidos com codornas em relação aos valores normalmente usados na formulação de rações para frangos de corte e poedeiras.

Parte dos resultados apresentados pode ser explicada pelo coeficiente de digestibilidade da matéria seca (CDMS) das misturas (DB+alimento teste). Apenas ocorreram melhoras nos CDMS das misturas em comparação com o resultado da DB $(69,1 \%)$ quando o milho $(73,7 \%)$ e a farinha de mandioca (76,6\%) foram incluídos em substituição a $30 \%$ da DB. Resultados intermediários foram apresentados pelo farelo de glúten $(68,3 \%)$, soja integral extrusada $(64,5 \%)$, farinha de peixe $(62,8 \%)$, farinha de vísceras $(62,7 \%)$, farelo de trigo $(62,1 \%)$ e do farelo de soja $(60,5 \%)$. O pior resultados obtido de CDMS em relação à DB foi o apresentado pela mistura DB com farinha integral de algaroba $(57,2 \%)$.

\section{Experimento 2. Ensaio de desempenho}

Com a finalidade de comparar a informação de energia metabolizável do milho e do farelo de soja usada para formular rações para frangos de corte e poedeiras, constantes em Rostagno et al. (2000), com os valores determinados no experimento um, utilizando codornas de 22 a 27 dias de idade e com aqueles obtidos por Furlan et al. (1998), utilizando codornas aos 65 dias de idade, foi realizado um ensaio de desempenho na fase de postura. Os resultados estão apresentados na Tabela 5.

Não houve efeito significativo dos tratamentos sobre as variáveis estudadas $(\mathrm{P}>0,05)$, indicando que tanto os valores energéticos do milho e do farelo de soja determinados com codornas ou frangos de corte e poedeiras podem ser utilizados para compor as rações de codornas em postura. Entretanto, pode-se inferir que houve pequena superioridade $(6,5 \%) \mathrm{em}$ valores absolutos na produção de ovos daquelas codornas que receberam ração formulada com o conteúdo energético para o milho e farelo de soja estimado por Furlan et al. (1998) em relação às demais.

Novamente, a ração formulada com valores energéticos determinados com codornas aos 65 dias de idade melhorou a conversão alimentar pela massa de ovos, respectivamente, em 12 e $7 \%$, em valores 
Tabela 5 - Consumo de ração (CR), produção de ovos (PR), peso do ovo (PO), massa de ovo (MO), conversão por massa $(\mathrm{CM})$ e por dúzia de ovos (CDZ) de codornas européias alimentadas com dietas balanceadas com energia metabolizável aparente $\mathrm{N}$ corrigida (EMAn) usada para frangos de corte e poedeiras, codornas em crescimento e adultas

Table 5 - Feed intake (FI), egg production (EP), egg weight (EW), egg mass (EM), feed egg mass conversion (EMC) and feed egg dozen conversion (EDC) of European quails fed diets formulated with corrected $N$ apparent metabolizable energy obtained with broiler chicks, gowing quails and quail hens

\begin{tabular}{lcccccc}
\hline Energia da dieta/espécie & $\mathrm{CR}(\mathrm{g})$ & $\mathrm{PR}(\%)$ & $\mathrm{PO}(\mathrm{g})$ & $\mathrm{MO}(\mathrm{g})$ & $\mathrm{CM}(\mathrm{g} / \mathrm{g})$ & $\mathrm{CDZ}(\mathrm{g} / \mathrm{dz})$ \\
Energy ofdiet/specie & $F I$ & $E P$ & $E W$ & $E M$ & $E M C$ & $E D C$ \\
\hline $\begin{array}{l}\text { EMAn frangos, } \\
\text { Broiler chicks AMEn }\end{array}$ & 34,2 & 81,60 & 12,66 & 10,33 & 3,312 & 0,41 \\
$\begin{array}{l}\text { EMAn - codornas jovens } \\
\text { Young quail AMEn }\end{array}$ & 31,2 & 81,60 & 12,14 & 9,91 & 3,15 & 0,36 \\
$\begin{array}{l}\text { EM - codornas adultas } \\
\text { Old quail AMEn }\end{array}$ & 32,6 & 87,20 & 12,69 & 11,06 & 2,95 & 0,37 \\
CV $(\%)$ & 8,87 & 5,97 & 3,22 & 6,93 & 7,23 & 8,27 \\
\hline
\end{tabular}

absolutos, em relação as rações formuladas com a energia do milho e do farelo de soja determinada com frangos de corte e com a energia destes ingredientes determinada com codornas de 22 a 27 dias de idade.

\section{Conclusões}

Os valores de EMA e EMAn ( $\mathrm{kcal} / \mathrm{kg}$ ) determinados para os alimentos de origem vegetal foram, respectivamente, 3.340 e 3.354 para o milho moído, 2.718 e 2.456 para o farelo de soja, 3.453 e 3.084 para a soja integral extrusada, $1.624 \mathrm{e} 1.593$ para o farelo de trigo, 4.558 e 3.992 para o farelo de glúten de milho, $3.329 \mathrm{e}$ 3.378 para a farinha de mandioca e 1.238 e 1.223 para a farinha integral da vagem de algaroba.

Para os alimentos de origem animal foram, respectivamente, 2.874 e 2.453 para a farinha de peixe e 3.090 e 2.791 para a farinha de vísceras.

Os valores energéticos do milho e do farelo de soja estimados para frangos de corte e poedeiras podem ser utilizados para compor rações de codornas poedeiras.

\section{Literatura Citada}

AGRICULTURAL RESEARCH COUNCIL - ARC. The nutritional requirement of ruminant livestock. London: CAB International, $1980.351 \mathrm{p}$.

FURLAN, A.C.; ANDREOTTI, M.O.; MURAKAMI, A.E. et al. Valores energéticos de alguns alimentos determinados com codornas japonesas (Coturnix coturnix japonica). Revista Brasileira de Zootencia, v.27, n.6, p.1147-1150, 1998.
HILL, F.W.; ANDERSON, D.L. Comparison of metabolizable energy and productive energy determination with growing chicks. Journal of Nutrition, v.64, p.587-604, 1958.

MATTERSON, L.B.; POTTER, L.M.; STURTZ, N.W. et al. The metabolizable energy of feed ingredients for chickens. Storrs: The University of Connecticut, Agricultural Experiment Station, 1965. p.3-11. (Research Report, 7)

MURAKAMI, A.E.; FURLAN, A.C. Pesquisa na nutrição e alimentação de codornas em postura no Brasil. In: SIMPÓSIO INTERNACIONAL DE COTURNICULTURA, 1., 2002, Lavras. Anais... Lavras: Universidade Federal de Lavras, 2002. p.113-120.

NATIONAL RESEARCH COUNCIL - NRC. Nutrient requirements of poultry. Washington, D.C.: National Academy of Science. 9.ed. 1994. 155p.

PENZJR., A.M.; KESSLER, A.M., BRUGALLI, I. Novos conceitos de energia para aves. In: SIMPÓSIO INTERNACIONAL SOBRE NUTRIÇÃO DE AVES, 1999, Campinas. Anais... Campinas: FACTA, 1999. p.1-24.

ROSTAGNO, H.S.; ALBINO, L.F.T.; DONZELE, J.L. Tabelas brasileiras de exigências nutricionais para aves e suínos (Composição de alimentos e exigências nutricionais). Viçosa, MG: Universidade Federal de Viçosa, 2000. 141p.

SILVA, D.J. Análise de alimentos (Métodos químicos e biológicos). 2.ed.Viçosa, MG: Universidade Federal de Viçosa, 1990. 150p.

SILVA, J.H.V.; RIBEIRO, M.L.G. Tabela nacional de exigência nutricional de codornas. Bananeiras, PB. DAP-CFT-UFPB. 2001. 19p.

UNIVERSIDADE FEDERAL DE VIÇOSA - UFV. SAEG (Sistema para análise estatística e genética) vs. 5.0. CPD/UFV. Viçosa, MG, 1983. 59p. 